\title{
Moderately severe hemophilia A
}

INSERM

\section{Source}

INSERM. (1999). Orphanet: an online rare disease and orphan drug data base.

Moderately severe hemophilia A. ORPHA:169805

Moderately severe hemophilia A is a form of hemophilia A (see this term) characterized

by factor VIII deficiency leading to abnormal bleeding as a result of minor injuries, or following surgery or tooth extraction. 